Correction

\title{
Correction: Ardia, D., et al. Return and Risk of Pairs Trading Using a Simulation-Based Bayesian Procedure for Predicting Stable Ratios of Stock Prices. Econometrics 2016, 4, 14
}

\author{
David Ardia ${ }^{1,2}{ }^{\oplus}$, Lukasz T. Gatarek ${ }^{3}$, Lennart Hoogerheide ${ }^{4}$ and Herman K. Van Dijk ${ }^{4,5, *}$
}

1 Institute of Financial Analysis, University of Neuchatel, 2000 Neuchatel, Switzerland; david.ardia@unine.ch 2 Department of Finance, Insurance and Real Estate, Laval University, Quebec City, QC G1V 0A6, Canada

3 Institute of Econometrics and Statistics, Faculty of Economics and Sociology, University of Lodz, 90-255 Lodz, Poland; gatarek@tlen.pl

4 Department of Econometrics and Tinbergen Institute, Vrije Universiteit Amsterdam, 1081 HV Amsterdam, The Netherlands; 1.f.hoogerheide@vu.nl

5 Econometric Institute, Erasmus University Rotterdam, 3062 PA Rotterdam, The Netherlands

* Correspondence: hkvandijk@ese.eur.nl; Tel.: +31-(0)10-4088900

Received: 1 February 2020; Accepted: 2 February 2020; Published: 5 February 2020

The authors wish to make the following corrections to this paper (Ardia et al. 2016):

Add a funding section at the end of the main text, "Funding: This research was funded by the National Science Center, Poland, grant number 2013/09/N/HS4/03751".

The authors would like to apologize for any inconvenience caused to the readers by the change. The change does not affect the scientific results. The manuscript will be updated and the original will remain online on the article webpage, with a reference to this correction.

\section{References}

Ardia, David, Lukasz T. Gatarek, Lennart Hoogerheide, and Herman K. Van Dijk. 2016. Return and Risk of Pairs Trading Using a Simulation-Based Bayesian Procedure for Predicting Stable Ratios of Stock Prices. Econometrics 4: 14. [CrossRef]

(C) 2020 by the authors. Licensee MDPI, Basel, Switzerland. This article is an open access article distributed under the terms and conditions of the Creative Commons Attribution (CC BY) license (http://creativecommons.org/licenses/by/4.0/). 